\title{
ENTRE RUPTURAS E CONTINUIDADES: UM ESTUDO SOBRE O PROCESSO DE RESSIGNIFICAÇÃO DO EMPREGO BANCÁRIO PÚBLICO.
}

\section{BETWEEN DISRUPTIONS AND CONTINUITIES: A STUDY ABOUT THE PROCESS OF RESSIGNIFICATION OF THE PUBLIC BANK EMPLOYMENT}

Fernando Ramalho Martins ${ }^{1}$

\section{RESUMO}

A presente pesquisa teve como objetivo investigar as percepções e significados atribuídos ao emprego bancário público por trabalhadores de um banco federal. $\mathrm{O}$ primeiro movimento foi analisar, por meio de uma revisão da literatura, o processo de reestruturação produtiva, iniciado na década de 1990. Num segundo momento, via análise de documentos disponíveis no Centro de Documentação do Sindicato dos Bancários de São Paulo, buscamos caracterizar os principais fatos e mudanças ocorridos no banco pesquisado durante a década de 1990. Por fim, vinte entrevistas semi-estruturadas foram realizadas, sendo: dez com Escriturários, ou seja, funcionários contratados na primeira metade da década de 1990, ou em período anterior, e que, por isso, vivenciaram a reestruturação produtiva no setor bancário; e dez com Técnicos Bancários, isto é, funcionários que ingressaram no banco por meio do concurso de 1998 ou de concurso posterior. Constatamos que para a nova geração de bancários a percepção oriunda de uma comparação sincrônica, na qual o emprego aparece como uma alternativa diante de experiências de trabalho temporário, instável ou flexível, parece amoldar a percepção advinda de uma análise diacrônica, que evidencia as perdas históricas do emprego bancário. É dessa maneira, que a estabilidade, sobretudo para os Técnicos Bancários, dissociada da remuneração e do status, se agiganta, tornando-se o elemento central no processo de re-significação do emprego bancário público.

Palavras-chave: Setor bancário - Reestruturação - Percepção do emprego bancário público.

\section{ABSTRACT}

The object of this study is the perceptions and meanings attributed to the public bank employment by employees of a federal bank. The first step was to analyze the productive restructuring process on the sector and its implications on work and workers. The second step was to try to characterize the major facts and changes occurred in the bank during the 1990s and early 2000s, via analysis of documents available at Centro de Documentação do Sindicato dos Bancários de São Paulo (documentation department of to the bank workers union in São Paulo). Finally, semi-structured interviews were carried out with two groups of workers; group one consisted of ten clerks; group two consisted of ten bank technicians, representing the new generation of bank workers, hired after the 1998 recruitment process. As a result, we found that, for the new generation of bank workers, the perception originated from a synchronic comparison, where the job appears as an alternative to temporary, unstable or flexible work experiences, seems to shape the perception 
originated from a diachronic analysis, which evinces the historical losses of bank work. The stability, now dissociated from status and salary, has been perceived as the central point in the opinion of clerks and banc technician when they define this job.

Keywords: Bank sector - bank restructuring - perception of a state bank employment.

\section{INTRODUÇÃO}

A década de 1990 foi um período de intensas mudanças para o setor bancário, marcado pela fusão, aquisição e privatização de bancos públicos; intensificação do trabalho; expressiva extinção de postos formais de trabalho, precarização das relações trabalhistas, terceirizações e deterioração do padrão de assalariamento; e, ao final, pela recuperação dos lucros. Diante desse contexto, esta pesquisa teve como objetivos investigar e analisar como os trabalhadores de um banco público federal percebem o emprego bancário após as mudanças decorrentes do processo de reestruturação da década de 1990.

Partimos de duas hipóteses inter-relacionadas. A primeira é que a reestruturação produtiva afetou negativamente o modo como o emprego bancário público passou a ser percebido pelos bancários, culminando em um processo de ressignificação. No entanto, como segunda hipótese, acreditamos que a ressignificação do emprego bancário público pelos bancários só pode ser compreendida à luz de um processo de significativas mudanças ideológicoinstitucionais inerentes ao capitalismo flexível. Entendemos que, em alguma medida, a ressignificação do emprego bancário público, forjada sob o contexto ideológicoinstitucional do capitalismo contemporâneo, figura importante papel na compreensão das respostas dos trabalhadores às transformações que vêm ocorrendo no setor, dentre as quais a própria aceitação, ainda que parcial ou relativa, da intensificação do trabalho.

Para a verificação dessas hipóteses, o primeiro movimento desta investigação consistiu em analisar os novos padrões de utilização da força de trabalho no contexto da reestruturação econômica do período em referência. Em um segundo momento, buscou-se, por meio da análise de documentos disponíveis no Centro de Documentação do Sindicato dos Bancários de São Paulo, analisar os 
principais fatos e mudanças ocorridos no banco pesquisado (doravante Banco $\mathrm{X}$ ou X), durante a década de 1990. Por fim, vinte entrevistas semiestruturadas foram realizadas com dois grupos de trabalhadores: o primeiro, formado por dez empregados que aderiram à carreira bancária como Escriturários, contratados por volta de 1990, tendo vivenciado o processo de reestruturação levado a cabo nessa década; e o segundo grupo, formado por dez empregados que ingressaram como Técnicos Bancários, nova denominação cunhada para os contratados a partir do ano de 1998.

\section{A DÉCADA DE 1990, A REESTRUTURAÇÃo PRODUTIVA E AS NOVAS FORMAS DE ORGANIZAÇÃO DO TRABALHO}

Os anos 1990 representaram um período de grande importância para a história econômica do país em geral e para o setor bancário nacional em particular. A importância histórica dessa década deve-se aos movimentos políticos e econômicos ocorridos em um contexto caracterizado, a princípio, por uma economia desestabilizada e com elevadas taxas inflacionárias. No início desse período, o governo brasileiro lançou mão de uma série de políticas de caráter neoliberal, cujos resultados foram, em linhas gerais, a abertura comercial e a internacionalização da economia (ARAÚJO; CARTONI; JUSTO, 2001). Nesse contexto, diversas instituições bancárias que não se (re)adaptaram ao novo ambiente competitivo faliram ou foram adquiridas por instituições maiores. As crises do Banco Econômico, em agosto de 1995, e do Banco Nacional, em novembro de 1995 (respectivamente, quarto e terceiro maiores bancos no ranking nacional), sinalizavam uma crise sistêmica no setor (CORAZZA, 2008).

Frente a esse contexto, tem-se início um processo de reestruturação do sistema financeiro no Brasil, coordenado pelo Banco Central, que resultou, em linhas gerais, em três tipos ou modalidades de ajustes (SEGNINI, 1999). A primeira modalidade diz respeito ao número de empresas no setor, destacando-se o processo de incorporações, fusões e privatizações de bancos nacionais, o qual possibilitou a expansão da participação do capital estrangeiro no sistema bancário. Assim, faz-se necessário destacar os dados apresentados por Brito, Batistella e Famá (2005) acerca do declínio no número de bancos durante o período de 1994 a 
2002, indo de 246 bancos para 167.

A segunda modalidade de ajustes diz respeito às mudanças ocorridas na composição dos produtos bancários, as quais "se referem às estratégias do setor objetivando a manutenção e a ampliação das carteiras de clientes e de lucratividade, num contexto de intensa concorrência entre os bancos" (SEGNINI, 1999, p.187). Jinkings (2002), nessa direção, defende que, no período de implementação do plano real, os bancos foram forçados a adotar novas estratégias de rentabilidade, devido a mudanças no quadro econômico ocasionadas pelos programas de ajuste financeiro e combate à inflação. Dentre essas novas estratégias, a autora destaca: 1) a expansão das atividades do setor para atividades que não se restringem ao âmbito financeiro, tais como: serviços de intermediação de negócios e engenharia financeira; 2) a venda de produtos financeiros e a cobrança de tarifas bancárias; 3) a redefinição do perfil operacional, "segmentando a clientela e restringindo os serviços e produtos mais sofisticados às camadas sociais de renda mais elevada, consideradas 'clientes preferenciais'” (JINKINGS, 2002, p. 46).

Por fim, a terceira modalidade de ajuste refere-se às mudanças ocorridas no "aparato regulatório do sistema bancário, envolvendo mudanças no sistema de garantia de crédito" (SEGNINI, 1999, p. 187, grifos nossos). Destacam-se que: 1) o total de ativos necessários à abertura de um banco foi aumentado para $32 \%$ em 1996; 2) o Banco Central passou a ter maior poder de intervenção na administração dos bancos.

Somadas a essas mudanças de caráter macroambientais, uma série de adaptações, em nível organizacional, tem início. Assim, um sistema de gerenciamento da força de trabalho mais alinhado a um modelo flexível de gestão desta encontra solo fértil para assentar suas raízes, passando a ser um importante fator no processo de organização do trabalho. Segundo Jinkings (2002), os programas de "Qualidade Total" foram introduzidos nos bancos estatais nos primeiros anos da década de 1990, buscando inserir, nesse contexto, a mesma lógica norteadora das instituições privadas, isto é, a lógica do mercado.

Como resultado dessa série de mudanças, houve, em primeiro lugar, uma forte redução no número de trabalhadores do setor bancário durante a década de 1990. Nesse sentido, conforme dados apresentados por Segnini (1999, p. 190), podemos observar um período de queda acentuada no número de empregos no 
setor financeiro, sobretudo no período que vai de 1989 a 1996. Se, no primeiro período, o número de empregados era de pouco mais de 800 mil, no segundo período passa a ser de aproximadamente 500 mil. É interessante notar também a diminuição no número de trabalhadores por posto de atendimento, indicando uma menor necessidade de mão de obra e comprovando, em certo sentido, a eficiência organizacional das mudanças realizadas. Assim, conforme Antunes (2001, p. 45), durante o período de 1990 a 1999, as médias de empregados por agência e por ponto de atendimento caíram, respectivamente, de 43,3 para 25,3 e de 28,2 para 17,4 .

Acompanhando o cenário de redução de postos de trabalho e de tendência de queda na remuneração média da categoria, que caracterizou a década de 1990, houve, por fim, a privatização, liquidação ou federalização (visando à futura privatização) de vinte bancos estatais (JINKINGS, 2002). Em síntese, três fenômenos caracterizam o processo de reestruturação no setor bancário: 1) desemprego; 2) terceirização e precarização do trabalho, e 3) intensificação do trabalho (SEGNINI, 1999).

De modo geral, analisando os impactos e efeitos de todo o processo de reestruturação do setor bancário, vemos que este se mostrou bastante positivo do ponto de vista dos bancos e banqueiros, considerando-se, em especial, a recuperação dos resultados negativos ocorridos durante os anos de 1995 e 1996, e a tendência de crescimento no lucro desse setor, que se concretiza, sobretudo, a partir do ano de 2002 e, em 2006, quase atinge a marca de $R \$ 30$ bilhões (DIEESE, 2007, p.7).

\section{A DÉCADA DE 1990 PARA O BANCO X}

A década de 1990 foi um momento bastante controverso para o Banco X e seus bancários, no qual a imagem de instituição pública, grande, lenta, pesada e ultrapassada passa a ser constantemente atribuída ao banco, cuja imagem associava-se a um "Grande Mamute" (O MAMUTE..., 1992) ou ao automóvel Galaxie, "enorme, reluzente e gastador" (SOARES, 1992, p. 84).

No início daquela década, diante de um prejuízo estimado em US $\$ 3,5$ milhões (SOARES, 1992), o Banco Central sugeria "soluções emergenciais e 
estruturais" para o banco (CORRÊA, 1992, p. 84). Após a substituição do presidente dessa instituição, era anunciado um pacote de ajuste econômico e financeiro, visando modernizar, capitalizar e revitalizar a instituição (CALMON, 1992; PRADO, 1992), que incluía políticas como: fechamento de 149 agências do interior do país, dispensa de estagiários, boys e funcionários terceirizados (FREIRE, 1994). Foi ainda nesse período, marcado pelo governo Collor de Mello e pela "caça aos marajás", que ocorreu a demissão de 2.500 empregados do $X$, os quais se encontravam em estágio probatório (ENTULHOS, 2010).

Como fruto dessas mudanças, os primeiros sinais de melhoria foram anunciados em outubro de 1994. Estimava-se em $\mathrm{R} \$ 70$ milhões por mês a redução da despesa administrativa alcançada pela empresa (CRISTINO; TRINDADE, 1994) e lucro de CR \$43,643 bilhões referente ao exercício de 1993 (MATTOS, 1994). Em dezembro de 1994, o então Ministro da Previdência assumia o comando do X e colocava como desafio retomar o perfil de banco público, porém, ao mesmo tempo, sem deixar de lado sua face comercial.

Em meados da década de 1990, os custos burocráticos eram denunciados pela imprensa: "De cada três funcionários do $X$, um é chefe. São quase 2 mil agências em todo o país, 65 mil empregados concursados, mais 40 mil prestadores de serviços (...). O governo se assusta com o luxo" (DESPERDícIO..., 1995). Cristino (1995) denunciava que a matriz e as superintendências do banco eram "verdadeiros castelos da burocracia". O custo do corpo funcional também fora objeto de denúncia. De acordo com Sousa (1996), o custo médio mensal dos funcionários do $X$ era o maior do mercado ( $R \$ 1.634,00$ por mês), ao passo que o custo médio mensal dos funcionários do Bradesco, por exemplo, era de $\mathrm{R} \$ 926,00$. Durante a greve de 1995, em represália aos grevistas, uma portaria cortando duzentos Cargos Comissionados foi assinada pelo presidente. Ainda no final daquele ano, era anunciado o Programa de Demissões Voluntárias do banco, cujo objetivo consistia em reduzir o quadro funcional em 10\% (SOUSA, 1995).

Em 1996, um lucro líquido de $\mathrm{R} \$ 221,3$ milhões (referente ao exercício de 1995) era anunciado, frente a um prejuízo de $R \$ 4$ bilhões do Banco do Brasil (A BUSCA..., 1996). Segundo Alves e Fernandes (1996), "o ajuste das contas foi obtido à custa de muito esforço", destacando-se: a) a eliminação de seis mil cargos comissionados e a demissão de funcionários contratados (terceirizados) e 
estagiários, o que fez que a empresa passasse a ter 99,8 mil funcionários em lugar de 112,8 mil; b) a renegociação dos $R \$ 20$ bilhões de dívidas atrasadas de estados e municípios, de modo que o $X$ recebeu, aproximadamente, $R \$ 2$ bilhões de prefeituras e governos estaduais no ano de 1995; c) a renegociação de dívidas de, aproximadamente, $\mathrm{R} \$ 1,7$ bilhões das sociedades de crédito imobiliário liquidadas no passado pelo Banco Central.

Diante de um lucro mais modesto referente ao exercício de 1996 e como forma de aumentar sua rentabilidade, o $\mathrm{X}$ incorporou, a partir de 1997, as casas lotéricas como canais alternativos de atendimento (GRAMACHO, 1997). Com isso, desafogou-se grande parte do atendimento bancário a um custo bastante interessante e inferior ao do atendimento na agência tradicional: pagava-se entre $R \$$ 0,10 e $R \$ 0,18$ por conta recebida na lotérica.

Em 1998, em tom de denúncia, Freitas (1998), atribuía à passividade do governo FHC "a quebra da estabilidade [do funcionalismo público] e os três a quatro anos sem correção". Destacava, ainda, o jornalista que "o assombro, porém, é que tudo acontece sem reação. (...) Os raros atos de protesto, no entanto, contam só com punhadinhos compostos pelos minguados protestadores de sempre". No que diz respeito às greves, a revista FENAE Agora (REAÇÃO..., 1998), à luz de um estudo do Dieese e frente a uma taxa de desemprego de 16,6\% no ano de 1997, atribuía ao medo do desemprego a diminuição no número de greves ocorridas no país em 1997.

Foi nesse contexto que se criou um novo Plano de Cargos e Salários (PCS) destinado aos Técnicos Bancários, designação conferida para diferenciar os novos bancários concursados dos Escriturários. Dentre as diferenças entre os PCS dos Técnicos Bancários em relação ao PCS dos Escriturários, destacamos:

Tabela 1: Plano de Cargos e Salários (PCS)

\begin{tabular}{|l|c|c|}
\hline & PCS Escriturários & PCS Técnicos Bancários \\
\hline Teto & $2.483,00$ & $1.051,00$ \\
\hline Níveis & $78^{2}$ & 15 \\
\hline Promoção & Mérito e antiguidade ${ }^{3}$ & Antiguidade \\
\hline
\end{tabular}

Fonte: FENAE Agora, (HISTÓRICO..., 2008, p. 18)

Como visto, não se tratava de mera mudança semântica, mas sim da 
criação de duas diferentes categorias de trabalhadores, ainda que desempenhassem tarefas idênticas. A criação do cargo de Técnico Bancário foi, a nosso ver, o marco (simbólico e institucional) fundamental de um processo que representa o nascimento de uma nova geração de bancários, cuja identidade profissional passa a ser forjada em meio a um novo padrão de relações de trabalho.

Foi nesse cenário que, em julho de 1999, a revista da Federação Nacional das Associações do Pessoal do banco (FENAE) avaliava que as políticas adotadas pela empresa - a venda de ações da empresa de seguros do $X$, a terceirização crescente dos serviços bancários e a criação de um novo plano de aposentadoria baseado na ideia de contribuições definidas em lugar de benefícios definidos - eram indícios de que o banco estava sendo preparado para ser privatizado (DIREÇÃO..., 1999). Muito embora a privatização não tenha chegado às vias de fato, a pressão exercida pelos seus defensores deixou suas marcas. Dentre elas, podemos destacar o RH 008, lançado em 2000, o qual demarcou uma importante alteração na relação entre capital e trabalho na instituição. De acordo com o Banco X (NEGOCIAÇÃO..., 2006), o RH 008 "foi um manual normativo que disciplinou a demissão sem justa causa no X." Esse dispositivo foi criado em 2000, tendo sido extinto no ano de 2003 , em atendimento às reivindicações da categoria.

Por fim, destacamos, ainda, que no ano de 1999 ocorreu o reajuste de 1\% nos salários, considerado um avanço por Ubiratan Campos do Amara, diretor da Confederação Nacional dos Trabalhadores nas Empresas de Crédito, pois significou a quebra de um jejum de três anos sem reajustes salariais (1996, 1997 e 1998), rompendo com a política de congelamento salarial iniciada em 1996 (CASTANHEIRAS, 1999).

\section{O SIGNIFICADO dO EMPREgo BANCÁRIO PÚBLICO: RELATOS DE ESCRITURÁRIOS E DE TÉCNICOS BANCÁRIOS}

Após a análise das mudanças ocorridas durante a década de 1990 no setor bancário e também da apresentação de alguns dos fatos que caracterizaram a história do banco $\mathrm{X}$ durante aquele período, passaremos agora a analisar os relatos das duas categorias de trabalhadores existentes no contexto do banco analisado: os Escriturários, trabalhadores contratados antes de 1998, e os Técnicos Bancários, 
trabalhadores contratados após 1998.

Para as finalidades deste artigo, focaremos nossa atenção na percepção desses dois grupos de trabalhadores em relação ao emprego bancário público. Assim, apresentaremos parte do resultado da nossa pesquisa de campo realizada durante os anos de 2009 e 2010. Abaixo apresentamos duas tabelas-resumo com o perfil dos empregados entrevistados.

Tabela 2: Perfil dos Escriturários entrevistados

\begin{tabular}{|c|c|c|c|c|c|c|c|}
\hline Entrevistado & Sexo & Idade & Estado Civil & Escolaridade & Pós-graduação & Admissão & Cargo \\
\hline Adão & M & 51 & Casado & $\begin{array}{c}\text { Superior Completo: } \\
\text { Engenharia Civil }\end{array}$ & Não & 1989 & Escriturário \\
\hline Érika & $\mathrm{F}$ & 43 & Casada & $\begin{array}{c}\text { Superior Completo: } \\
\text { Contabilidade }\end{array}$ & $\begin{array}{c}\text { Gestão } \\
\text { Empresarial }\end{array}$ & 1990 & $\begin{array}{l}\text { Analista } \\
\text { Júnior } 8 \mathrm{~h}\end{array}$ \\
\hline Isaac & M & 51 & Casado & $\begin{array}{c}\text { Superior Incompleto: } \\
\text { Economia, Engenharia, } \\
\text { Gestão de Pessoas }\end{array}$ & Não & 1990 & Escriturário \\
\hline João & M & 54 & Casado & $\begin{array}{c}\text { Superior Completo: } \\
\text { Tecnologia Civil }\end{array}$ & Não & 1984 & $\begin{array}{l}\text { Analista } \\
\text { Sênior } 8 \mathrm{~h}\end{array}$ \\
\hline Maria & $\mathrm{F}$ & 51 & Divorciada & Superior Completo. & Recursos Humanos & 1990 & $\begin{array}{c}\text { Técnico de } \\
\text { RH } \\
\end{array}$ \\
\hline Mário & M & 52 & Casado & Superior Completo & Não & 1982 & $\begin{array}{c}\text { Escriturário } \\
\text { Superior }\end{array}$ \\
\hline Marta & $\mathrm{F}$ & 51 & União Estável & $\begin{array}{c}\text { Superior Completo: } \\
\text { Fisioterapia }\end{array}$ & Não & 1982 & $\begin{array}{l}\text { Analista } \\
\text { Júnior } 8 \mathrm{~h}\end{array}$ \\
\hline Pedro & M & 51 & Casado & Superior Completo & Finanças & 1990 & $\begin{array}{l}\text { Analista } \\
\text { Pleno 8h }\end{array}$ \\
\hline Rosa & $\mathrm{F}$ & 43 & Casada & $\begin{array}{c}\text { Superior Completo: } \\
\text { Direito }\end{array}$ & Não & 1989 & $\begin{array}{c}\text { Técnico de } \\
\text { RH } \\
\end{array}$ \\
\hline Vagner & M & 50 & Casado & $\begin{array}{c}\text { Superior Completo: } \\
\text { Direito }\end{array}$ & $\begin{array}{c}\text { Gestão } \\
\text { Empresarial }\end{array}$ & 1982 & $\begin{array}{l}\text { Analista } \\
\text { Pleno } 8 \mathrm{~h}\end{array}$ \\
\hline
\end{tabular}

Tabela 3: Perfil dos Técnicos Bancários entrevistados

\begin{tabular}{|c|c|c|c|c|c|c|c|}
\hline Entrevistado & Sexo & Idade & Estado Civil & Escolaridade & Pós-graduação & Admissão & Cargo \\
\hline Abel & $M$ & 30 & Solteiro & $\begin{array}{c}\text { Superior Completo: } \\
\text { Direito }\end{array}$ & Não & 2006 & $\begin{array}{l}\text { Técnico } \\
\text { Bancário }\end{array}$ \\
\hline André & $M$ & 43 & União Estável & $\begin{array}{c}\text { Superior Completo: } \\
\text { Agronomia }\end{array}$ & Gestão Empresarial & 1998 & $\begin{array}{l}\text { Técnico de } \\
\text { Fomento } 8 \mathrm{~h}\end{array}$ \\
\hline Aparecida & $\mathrm{F}$ & 28 & Solteira & $\begin{array}{c}\text { Superior Completo: } \\
\text { Direito }\end{array}$ & Gestão de Pessoas & 2005 & $\begin{array}{l}\text { Técnico } \\
\text { Bancário }\end{array}$ \\
\hline Caio & M & 36 & Solteiro & $\begin{array}{c}\text { Superior Completo: } \\
\text { Engenharia Civil }\end{array}$ & Não & 2003 & $\begin{array}{l}\text { Técnico } \\
\text { Bancário }\end{array}$ \\
\hline Joana & $\mathrm{F}$ & 38 & Casada & $\begin{array}{c}\text { Superior Completo: } \\
\text { Tecnologia de } \\
\text { Processamento de } \\
\text { Dados }\end{array}$ & Informática & 2005 & $\begin{array}{l}\text { Técnico } \\
\text { Bancário }\end{array}$ \\
\hline Paulo & $M$ & 32 & Solteiro & $\begin{array}{c}\text { Superior Completo: } \\
\text { Administração }\end{array}$ & Não & 2008 & $\begin{array}{l}\text { Técnico } \\
\text { Bancário }\end{array}$ \\
\hline Roberta & $\mathrm{F}$ & 26 & Solteira & $\begin{array}{c}\text { Superior Completo: } \\
\text { Fonoaudiologia }\end{array}$ & Não & 2005 & $\begin{array}{l}\text { Analista } \\
\text { Júnior }\end{array}$ \\
\hline Simão & M & 31 & Solteiro & $\begin{array}{c}\text { Superior Completo: } \\
\text { Geografia }\end{array}$ & Geoprocessamento & 2000 & $\begin{array}{c}\text { Gerente de } \\
\text { Atendimento }\end{array}$ \\
\hline Teresa & $F$ & 31 & Casada & $\begin{array}{c}\text { Superior Completo: } \\
\text { Jornalismo }\end{array}$ & Não & 2007 & $\begin{array}{l}\text { Técnico } \\
\text { Bancário }\end{array}$ \\
\hline Tomé & $M$ & 43 & União Estável & $\begin{array}{c}\text { Superior Completo: } \\
\text { Geografia }\end{array}$ & Não & 2001 & $\begin{array}{l}\text { Técnico de } \\
\text { Fomento } 8 \mathrm{~h}\end{array}$ \\
\hline
\end{tabular}




\section{ESCRITURÁRIO: SER OU NÃO SER UM BANCÁRIO DO X?: IMPRESSÕES DE ONTEM E DE HOJE}

A fim de compreender o significado do emprego bancário público e de sua(s) mudança(s), indagamos os empregados escriturários acerca de suas percepções relacionadas à década de 1990 e dos significados de ser um bancário de uma instituição pública em dois momentos: no início de suas carreiras e na época atual.

De forma geral, a década de 1990 foi descrita como: momento de transição, de redefinição na empresa, na qual os administradores "botaram as mangas de fora no sentido de baratear os custos das agências" (Mário); o fim da época de ouro (Adão); árido como um deserto (Mário); trágico, pesado (Vagner); tenebroso, de medo, em que ocorreu um processo de desvalorização da categoria (Rosa); de retrocesso nas relações humanas, na qual os empregados tornavam-se mais "loucos" ao passo que os bancos tornavam-se mais lucrativos (Maria).

A deterioração das relações entre os colegas de trabalho e o crescimento do individualismo foram outros elementos apontados, processo este relacionado com a criação de "castas" e de bradescalização das relações de trabalho no banco, segundo Mário.

É interessante destacar que alguns dos entrevistados, ao serem indagados sobre os motivos das mudanças ocorridas em relação ao trabalho bancário, apontam para um contexto maior, ou seja, para um contexto que extrapola o banco. Nesse sentido, as mudanças são vistas como um movimento adaptativo, seja ao próprio mundo, porque "mudou o mundo. O mundo não é mais estanque" (Vagner); seja à Globalização (Maria, Mário, Adão, Vagner), "até porque, contra a Globalização, o que se espera?"; ou ao Neoliberalismo (Adão). No tocante a essa questão, os entrevistados apresentaram, de forma geral, um sentimento de impotência e de inevitabilidade, como expresso, por exemplo, na fala de Vagner:

Olha, eu não falo se ela [a mudança] é boa ou ruim, eu falo que ela é necessária. São mudanças necessárias, que não tem como evitar. E por mais que você esperneie e tal, [por mais] que [você] vai defender o seu corporativismo, chega um momento em que muda. Porque a mudança é contínua. A mudança ela vem mesmo. De uma forma ou de outra ela vem e você tem que se adaptar a ela. Não tem outro caminho... Ou você cai fora. Vem outra mudança aí? Vem! E daí? Você tem que se adaptar. 
A mudança, assim, está posta, não cabendo questionar suas determinações e seus efeitos sobre os trabalhadores. Ao sujeito isolado resta apenas a adaptação funcional às novas imposições do sistema. O não ajustamento assume um caráter de fraqueza do indivíduo, incapaz de atender ao imperativo de adaptação. O enfrentamento ou questionamento das mudanças é caracterizado como uma atitude infantil (o espernear de uma criança) ou corporativista, por seu caráter supostamente não realista. Em última análise, percebemos aqui um processo discursivo de legitimação das mudanças.

No tocante ao emprego bancário público em si, a existência de uma diferença entre o significado atual e o passado foi um ponto pacífico nas narrativas dos entrevistados. Diferença esta que é embasada no declínio salarial e de status da profissão.

A questão salarial é reiteradamente assinalada pelos entrevistados quando falam do início de suas carreiras no banco. De acordo com Pedro, "naquela época o bancário ganhava mais. Isso aí não tem discussão! O bancário, pelo menos o empregado do X, ganhava bem mais; conseguia mais coisas". Chama a atenção para a existência de décimo terceiro salário, que incidia inclusive nos tickets alimentação e refeição. Vagner, por sua vez, defende que "antigamente tinha o peso da remuneração que era melhor, bem melhor!"; Isaac acrescenta que "foi de um bom tempo para cá que [o salário] caiu muito", e João complementa que "se comparar o salário de vinte e cinco anos atrás com o de hoje, ele era muito maior. Era muito mais do que se ganha hoje. Então, daquela época para cá, nós viemos acumulando várias perdas salariais”. Rosa, por fim, compara o emprego do passado à atual carreira de um Promotor de Justiça. Em sua opinião, o emprego no $X$ "era assim, estável, o salário era muito bom, não se compara”.

No que concerne ao prestígio social da profissão, Rosa pondera que, atualmente, "já não é aquele status". Essa opinião é também partilhada por Pedro, Maria e Vagner. Pedro destaca que "não era qualquer um que trabalhava no Banco X, no Banco do Brasil. Então, você era destacado". Situação diferente da atual na qual, em sua opinião: "eu acho que hoje você não tem mais muito disso não. Defasou bastante. E o salário era muito bom". Maria destaca que, quando entrou no $X$, tinha a visão de que era muito difícil entrar em um banco público: "e hoje a gente já não tem mais essa... já não é dada mais essa importância que se dava ao status 
de ser um funcionário do Banco X". Vagner defende que o emprego no X "era um emprego bem cogitado perante a população. (...) Hoje também é respeitado, mas não tem aquele peso. (...) Antigamente tinha o peso da remuneração que era melhor". João complementa que se tratava de "um emprego almejado por muitos".

No entanto, é necessário ressaltar que a crítica ao declínio salarial é sempre ponderada quando se leva em conta o contexto socioeconômico atual. Dessa forma, Rosa, por exemplo, reconhece que "O salário de um TB é $R \$$ 1.400,00. Mas, por estar no $\mathrm{RH}$, a gente ainda sabe que tem muita gente que valoriza isso. Eu não cuspo no prato que eu como". Igual ponderação aparece também nas narrativas de outros entrevistados. Marta, dessa forma, considerando o contexto de uma cidade interiorana e levando em conta o próprio ambiente de trabalho (de área-meio e não de agência), declara que: "Aí você olha para a cidade e você fala: 'é um puta salário!' Porque é! $R \$ 1.300,00$ para poder trabalhar de calça jeans, de tênis. (...) Basta você bater o ponto, não perturbar ninguém, não roubar, ser cordial e pronto, você fica". Por fim, Mário nos lembra que "ainda hoje, em relação aos bancos privados, continua sendo menos mal que nos bancos privados. (...) é claro que ainda hoje existe uma diferença tremenda entre você ser um bancário de banco público e ser um bancário de um banco privado. Nós estamos em um período de greve e você está vendo a diferença".

Outro interessante ponto que surge nos depoimentos diz respeito às percepções sobre as mudanças ocorridas no relacionamento entre os empregados. De acordo com o moderno discurso organizacional, esperava-se encontrar um ambiente bastante propício à cooperação entre os funcionários, devido à necessidade de promover o trabalho em equipe. Em princípio, parece que a percepção dos entrevistados não segue nessa direção. Nesse sentido, Marta enfatiza a diferença entre o discurso e a prática: "Que é diferente de quando falam lá na área onde estou, ah, isso tem que ser um trabalho em equipe. Ah, dá vontade de falar assim, vai tomar banho! [risos] Isso daí é da boca pra fora." De modo geral, a principal mudança percebida foi 0 aumento do individualismo, o qual é acompanhado da percepção de deterioração na qualidade da relação entre os colegas de trabalho. Marta defende que se trata de uma questão geracional, relacionada ao crescimento do que chama de "geração empregada" . Conforme destaca Maria, “antes, existia uma maior preocupação com o outro. (...) Hoje eu vejo 
muito individualismo. Antes existia mais amizade até nas relações de trabalho". Rosa, que trabalha na mesma unidade de Maria, apresenta um ponto de vista semelhante: "eu acho que antigamente tinha mais coleguismo do que hoje em dia. Parece que antigamente um não queria comer o fígado do outro para tentar subir. (...) A gente podia confiar em todo mundo". Pedro defende que as greves são um importante exemplo de como os empregados antigamente eram mais unidos. Para ele, "por exemplo, as greves daquele período eram fervorosas! Até as pessoas com funções, elas entravam em greve, o pessoal era mais unido". Nessa mesma direção, Érika, ratificando a opinião de Pedro, afirma que: "a gente ia [para a greve] com o objetivo de lutar pela classe. (...) eu sentia isso, que o pessoal era mais unido, todo mundo com aquela cabeça".

No que concerne à relação dos novos empregados com o emprego, duas posturas são identificadas por Isaac: a primeira, daqueles que, em geral, com menor idade, tomam o emprego como um bico "para pagar a faculdade, para fazer um outro concurso" ; a segunda relaciona-se àqueles que entram no banco com maior idade "só para não ficar parado, ou, então, para se aposentar". Érika defende que os novos bancários possuem uma perspectiva de transitoriedade, diferentemente do que ocorria com os Escriturários: "antigamente a gente entrava com o objetivo de ficar, porque o salário era bom, porque você sabia que tinha uma carreira para seguir dentro do X. Então, era uma coisa para a vida". Já para os novos empregados, "principalmente o pessoal novo, que nem você, (...) é como se fosse um trampolim! (...) 'ah, esse serviço, vou dar um tempo e depois vou estudar para outras coisas'”. As narrativas acima insurgem no contexto de comparação entre o antes e o depois, entre o que foi e o que é. Nesse sentido, o trabalho como provisório é um fenômeno atribuído por esses entrevistados ao contemporâneo, e não ao passado.

Isaac, como vimos, revela ainda a existência de um segundo grupo de novos bancários que também difere do grupo para o qual o trabalho é visto como provisório: este grupo é formado por aqueles que, mesmo sendo mais velhos, optam pelo banco. Em meio a um contexto de deterioração salarial e de status, resta a pergunta: o que leva tais pessoas a optar pelo setor bancário? O relato em questão nos permite apenas inferir algumas respostas: falta de opção frente a um mercado altamente competitivo; resquícios de memória acerca do emprego público em 
um passado já distante; estabilidade, visando à aposentadoria.

Os depoimentos dos escriturários acima expressam a ideia de carreira no serviço bancário público, tomando a transitoriedade como marca que os diferencia da nova geração de bancários. Contudo, convém notar, retomando a categorização de Romanelli (1978), que a perspectiva de transitoriedade era assumida por parte da geração dos Escriturários, e, em certo sentido, aparece nas próprias narrativas de alguns entrevistados ao tratarem do início de suas carreiras no banco. Assim, acreditamos que, para a grande maioria dos Escriturários entrevistados nesta pesquisa, o emprego bancário público, embora não tenha aparecido como a primeira opção de vida para a maioria deles, torna-se, ao longo do tempo, de fato, uma carreira.

Porém, o emprego de outrora não parece ser o mesmo oferecido aos novos bancários. Após o congelamento salarial e com o advento dos processos de criação de "castas", da bradescalização das relações de trabalho e do aumento do individualismo, a significação social do emprego parece não ser mais a mesma quando considerada historicamente. A dimensão da carreira, seja ela almejada de antemão ou construída com o tempo, parece estar se enfraquecendo. O emprego transitório, traduzido pela imagem de um "trampolim", capaz de assegurar uma condição que vá além da estabilidade, parece estar ocupando cada vez mais espaço na percepção de nossos entrevistados ao se referirem à relação dos Técnicos Bancários com o emprego bancário público.

\section{O EMPREgo No banco PÚBLICO FEDERAL NA PERCEPÇÃo dos TÉCNICOS BANCÁRIOS}

Aqui, um primeiro ponto que merece nossa atenção é o fato de que, para esses empregados, o ingresso no banco é explicado, mesmo que sem muito entusiasmo, como uma ascensão profissional e social que tem por base a comparação com a situação passada. No entanto, o ponto de apoio dessa ascensão parece estar se deslocando do tripé salário-status-estabilidade para, meramente, a questão da estabilidade. A estabilidade, assim, se apresenta como o grande motivador dos que procuram essa profissão, compensando até mesmo a perda histórica em termos salariais e de status. 
Nesse sentido, Joana considera o emprego no Banco $X$ como "um emprego normal", assim como Aparecida, quando afirma enxergar este "como um trabalho comum, como outro qualquer". Entretanto, é importante destacar que, mesmo que essa última tenha afirmado tratar-se de um emprego "qualquer", ela prontamente pondera que este significa "estabilidade! Não é mais status. Acho que a questão do status foi há muito, muito tempo atrás. Acho que quando meu pai entrou no Banco do Brasil; e ele já se aposentou". Paulo, um pouco mais enfático, defende que trabalhar no $X$ "não significa muita coisa não. O salário é muito baixo. É um salário que não... pelo menos o meu salário é do nível de operário. Então, o nível do status social é quase nenhum". Já Caio, mais ponderado, afirma que o significado de ser um bancário “(...) agora já está meio sucateado, vamos dizer, mas mesmo assim tem uma certa estabilidade. Dá para fazer planos a longo prazo. Porque você sabe que você não iria ser mandado embora como seria em um banco particular".

É interessante notar que, embora a questão da estabilidade pareça ser o grande denominador comum nas entrevistas, a questão do status também se mostra presente, mesmo que em menor grau. Ademais, diferentemente da estabilidade, 0 prestígio social aparece no relato dos entrevistados geralmente de modo ambíguo e relativo. Nesse sentido, é importante destacar o contexto social no qual tanto a questão do status quanto a questão salarial estão sendo consideradas. Parece que, na qualidade de primeiro emprego, para uma pessoa recém-formada, em um mercado de trabalho extremamente competitivo e com alto número de trabalhadores desempregados, o emprego no banco $X$ ainda mantém certo status, ao menos aos olhos dos familiares, conforme pode ser notado nos discursos de Roberta $e$ Aparecida, quando relatam a alegria de seus pais ao tomarem ciência da convocação delas para trabalhar no banco. No entanto, deixa claro o limite do reconhecimento desse status ao revelar que seus pais "pegam no seu pé até hoje: 'tem que estudar, tem que estudar. Tem que melhorar, tem que crescer, tem que sair de lá".

O limite da positividade desse emprego também é evidenciado no momento em que os Técnicos Bancários mostram-se reticentes quanto ao futuro profissional no banco. A grande maioria, com exceção dos dois funcionários que, coincidentemente, vivenciaram a experiência do emprego terceirizado no $X$, manifestou a intenção ou desejo de buscar outras oportunidades fora do banco. É 
essencial apontar que não se trata de quaisquer oportunidades, mas sim de oportunidades também estáveis, porém com melhores condições salariais e de status. Portanto, essas novas oportunidades almejadas parecem ter por base o tripé que outrora deu sustentação ao emprego bancário público. Entretanto, parece-nos que a recuperação do salário e do status também pode se dar por vias internas, ou seja, por meio dos Cargos Comissionados, justificando a hesitação dos Técnicos Bancários quanto aos seus futuros profissionais.

Dessa forma, constata-se a existência de uma relação segundo a qual: quanto mais reduzidas se mostrem as possibilidades internas de crescimento profissional, tanto mais forte torna-se a ideia (ou mito) do emprego bancário como uma passagem, tanto mais se renova a ideia do provisório. Todavia, a possibilidade de concretização dessa ideia está diretamente relacionada às condições externas de compra e venda da força de trabalho, o que, em última análise, determinará a transitoriedade ou permanência no banco.

A possibilidade (ou não) de crescimento profissional também parece estar diretamente associada à participação sindical dos novos bancários. Considerando o contexto no qual as condições para prosperar dentro do ambiente bancário são limitadas e a existência de uma política salarial é bastante desfavorável para aqueles que se encontram nos níveis mais baixos da hierarquia, a possibilidade de crescimento, agindo como uma força sedutora, parece influenciar na decisão de envolvimento ou não envolvimento com o sindicato, e, com isso, direcionando, em última análise, uma tensão antes em sentido vertical (entre trabalho e capital) para uma tensão horizontal (entre funcionários em igual nível hierárquico) (BURAWOY, 1979), como pode ser inferido a partir dos discursos de Aparecida: "Quando eu entrei no $X$, na área em que eu entrei, de 28 funcionários, apenas dois ou três participavam da greve. Havia, assim, uma pressão da gerência (...) Havia a nossa expectativa de crescimento. Mas o tempo vai passando, as fichas vão caindo".

A sedução exercida pela hierarquia funcional e salarial parece também impactar a própria ideia/ percepção de categoria, na medida em que concorre para sua cisão, podendo estar, em alguma medida, relacionada à questão do individualismo apontada pelos entrevistados da primeira etapa. Nessa direção, Paulo defende que "a categoria é cada um por si. Quem tem cargo não está nem aí; não faz greve, que eu veja... Não participa, porque ganha cinco, seis vezes mais do que 
o funcionário em início de carreira. Eles não reivindicam”. Conclui esse entrevistado que "quem precisa reivindicar é quem ganha pouco". Tomé avalia que o bancário médio pensa da seguinte maneira: "o sindicato não vai fazer nada por mim. Então eu tenho que puxar o saco aqui, fazer minhas coisas(...). O sindicato não vai resolver minha vida".

A nosso ver, tais constatações expressam-se no discurso de Roberta, ao revelar sua alienação em relação à participação nos movimentos reivindicatórios da categoria: "É uma coisa que não me interessa muito, apesar de que eu deveria". Como forma de solucionar esse "dilema", a entrevistada conclui que "eu também não penso em morrer no X, então eu nem...". Destacamos que essa afirmação reticente é reveladora de uma possível relação entre a percepção do emprego bancário mais como uma fase passageira do que como uma carreira propriamente dita, daí o seu não envolvimento nos movimentos formais de reivindicação no setor.

\section{CONSIDERAÇÕES FINAIS}

Após uma breve apresentação dos impactos da reestruturação produtiva da década de 1990 no setor bancário e no banco analisado, procurou-se analisar a percepção de dois grupos de bancários acerca do significado do emprego bancário em um banco público federal.

Quando indagados sobre o emprego analisado, notamos que, enquanto nos relatos dos Escriturários, ao falarem do início de suas carreiras, encontramos referências ao prestígio social associado ao emprego no Banco $\mathrm{X}$ e aos bons salários, os Técnicos Bancários referem-se a um salário que pode ser considerado razoável, enfatizando, em sua grande maioria, essencialmente, o vínculo estável de trabalho. Diante de tal quadro, surge a indagação: por que a estabilidade se sustenta como força central e catalisadora para os novos bancários do $X$ ? Não seria 0 processo de deterioração salarial e de status razão suficiente para repelir novos entrantes?

Parece-nos que as respostas a esses questionamentos devem ser buscadas a partir do entendimento das condições objetivas do atual mundo do trabalho e da reconfiguração das instituições e valores dentro do capitalismo contemporâneo. Assim, acreditamos que se deve levar em conta o fortalecimento do 
modelo de acumulação flexível que "se apoia na flexibilidade dos processos de trabalho, dos mercados de trabalho, dos produtos e padrões de consumo" (HARVEY, 1993, p. 140) e não mais na produção e no consumo em massa e no modelo de relação de trabalho normal (GODOY, 1991). Desse novo modelo, decorrem: o crescimento exponencial do trabalho (e do salário) hifenizado , passando a ocupar cada vez mais o lugar que antes cabia ao trabalho em tempo (e salário) integral (salário família) (BEYNON, 2002). Assim, acreditamos que a aceitação desse novo emprego bancário se dá tendo por base esse mundo novo do salário parcial, do contrato esporádico, dos laços fracos, da organização em rede e da empresa flexível (SENNETT, 2008), próprios da era do grande desengajamento (BAUMAN, 2003). Portanto, parece-nos que é à luz de experiências episódicas de trabalho que a estabilidade (mesmo estando manca devido à deterioração do salário e do status) destaca-se e sustenta-se nos discursos de nossos Técnicos Bancários. Dentre estas experiências, frisamos as que seguem: bolsista de mestrado (André); trabalhador casual que fazia bicos no ramo de informática (Simão); ex-bancário e Agente Censitário (Tomé); padeiro temporário (Caio); professor autônomo (Joana e Aparecida); ex-adolescente aprendiz e ex-trabalhador terceirizado de banco público (Abel, Teresa e Paulo); trabalhador de banco privado (Aparecida e André); e ainda para um recém-graduado sem emprego (Caio, Abel, Teresa, Roberta). Assim, a percepção oriunda de uma comparação sincrônica, na qual o emprego no $X$ aparece como uma alternativa diante de experiências de trabalho temporário, instável ou flexível, parece amoldar a percepção oriunda de uma análise diacrônica, que reconhece as perdas históricas do emprego bancário.

No entanto, dentro de um contexto de difícil obtenção de reconhecimento e de limitadas possibilidades de crescimento, o emprego bancário passa a ser visto, para o Técnico Bancário, antes como um emprego transitório do que como uma carreira propriamente dita, corroborando a tese segundo a qual o emprego bancário público trata-se mais propriamente de um intermezzo, ou, segundo palavras dos entrevistados, de uma passagem ou trampolim, o que evidencia, aqui, o limite do olhar positivo para com esse trabalho. Esse processo de ressignificação de emprego bancário público, certamente impacta sobre o envolvimento político e sindical dos trabalhadores bancários. Nesse sentido, acreditamos que as mudanças objetivas e subjetivas relacionadas a esse trabalho alimentam, por um lado, a percepção do 
aumento da competitividade e do individualismo entre aqueles que almejam ser "campeões" (MACHADO, 2002) e que, para tanto, devem se destacar da condição inicialmente assegurada pelo concurso, mas, por outro lado, provocam o sentimento de hesitação em relação à carreira bancária, que, em última análise, pode culminar no sentimento de "desencantamento" e perda da identidade com o "ofício bancário" (DRUCK, 2002). A nosso ver, tanto o desencantamento com o ofício bancário (e com a categoria), quanto a adesão ao novo ideário organizacional, sobretudo por parte daqueles que almejam compor a "casta" dos comissionados, figuram importantes elementos para compreender o menor envolvimento dos bancários nas ações político-sindicais.

Em síntese, o que parece nitidamente ter permanecido como elemento central da percepção e significação do emprego bancário no setor público foi a questão da estabilidade em um trabalho considerado pelos trabalhadores mais recentes como: "estruturado"; que oferece um "salário razoável" para um início de carreira ou considerando o contexto regional; visto com bons olhos pelos pais; e com "menor carga horária" (jornada de 6 horas diárias). Estabilidade esta, importante lembrar, muito valiosa quando consideradas as condições de trabalho dos empregados do setor privado ou mesmo considerando o atual mercado de trabalho, extremamente competitivo e incerto. Acreditamos que esta percepção parece ser essencial para o entendimento do porquê de os trabalhadores do banco estudado virem aceitando, mesmo que parcial ou relativamente, as mudanças organizacionais e a consequente intensificação do ritmo de trabalho em um contexto de desvalorização salarial e de reconhecimento social desse trabalho. 


\section{REFERÊNCIAS}

A BUSCA de ajuste nos bancos estatais. O Estado de São Paulo. São Paulo, 18 mar. 1996.

ALVES, R.; FERNANDES, C. Caixa Econômica fechou balanço do ano passado com lucro de R\$221,3 milhões. O Globo. Rio de Janeiro, 18 mar. 1996.

ANTUNES, L. R. Reestruturação produtiva e sistema bancário movimento sindical bancário brasileiro nos anos $\mathbf{9 0}$. Tese de doutoramento apresentada ao Instituto de Economia da UNICAMP. Campinas, 2001.

ARAÚJO, A. M. C.; CARTONI, D. M.; JUSTO, C. R. D. M. Reestruturação produtiva e negociação coletiva nos anos 90. Revista Brasileira de Ciências Sociais, v. 16, n. 45, fev. 2001.

BAUMAN, Z. Comunidade: a busca por segurança no mundo atual. Rio de Janeiro: Jorge Zahar Editor, 2003.

BEYNON, H. As práticas do trabalho em mutação. In: Antunes, R. (org.). Neoliberalismo, trabalho e sindicatos: reestruturação produtiva na Inglaterra e no Brasil. São Paulo: Boitempo Editorial, 2002, p. 9-38.

BRITO, G. A. S.; BATISTELLA, F. D.; FAMÁ, R. Fusões e aquisições no setor bancário: avaliação empírica do efeito sobre o valor das ações. RAUSP, São Paulo, v. 40, n. 4, p. 353-360, out./nov./dez. 2005.

BURAWOY, M. Manufacturing Consent: changes in the labor process under monopoly capitalism. Chicago: The University of Chicago Press, 1979.

CALMON, C. Saneamento da Caixa. Jornal do Brasil. Rio de Janeiro, 10 dez. 1992.

CASTANHEIRA, A. Funcionários da Caixa terão primeiro reajuste em 3 anos. Diário Popular. São Paulo, 12 mar. 1999.

CASTELLS, M. A Sociedade em rede. São Paulo: Paz e Terra, 2003. 
CORAZZA, G. Crise e Reestruturação Bancária no Brasil. Disponível em:<http://www.ufrgs.br/ppge/pcientifica/2000_08.pdf>. Acessado em: abr. 2008.

CORRÊA, M. Relatório revela desordem e crise na CEF. O Estado de São Paulo. São Paulo, 18 set. 1992.

CRISTINO, V. ; TRINDADE, R. Caixa vai tornar-se saudável. Jornal do Commercio. Rio de Janeiro, p. 21, 02 a 04 out. 1994.

CRISTINO, V.; ALENCAR, S. Arida defende reestruturação da Caixa. O Estado de São Paulo. São Paulo, 26 abr. 1995.

DESPERDícIO na CEF provoca susto no governo. O Estado de São Paulo. São Paulo, 04 jun. 1995.

DIEESE. O lucro recorde dos seis maiores bancos do país no primeiro semestre de 2007. Nota Técnica, n. 53, out. 2007.

DIREÇÃO da Caixa prepara a empresa para privatização. FENAE Agora, São Paulo, ano 2, n. 5, p. FA16, jul. 1999.

DRUCK. et. al. Bancário: um emprego de múltiplos riscos. Caderno CRH. Salvador, n. 37, p. 217-233, jul./dez. 2002.

ENTULHOS neoliberais em dose dupla. FENAE Agora, ano 13, n. 64, p. 18-23, maio/ jun. 2010.

FREIRE, G. CEF Vai Fechar 149 agências até o final de junho, mas não vai demitir. Gazeta Mercantil. São Paulo, 31 mar. 1994.

FREITAS, J. O mais assombroso. FENAE Agora. São Paulo. Ano 1. Número 1. Fev. 1998.

GODOY, L. Cambios en el mercado de trabajo y relaciones de pareja: el punto de vista de los hombres. In: Congresso da Asociación Latinoamericana de Sociología ALAS, 23, 2001, Antígua, Guatemala. Anais... Disponível em: $<$ http://dwt.oit.or.cr/index.php?option=com_docman\&task=doc_details\&gid=20\&ltemi $d=5>$. Acessado em: out. 2010. 
GRAMACHO,L. Um banco com 7.600 agências. Jornal do Brasil. Rio de Janeiro, p. 17, 24 abr. 1997.

HARVEY, D. A condição pós-moderna: uma pesquisa sobre as origens da mudança cultural. São Paulo: Loyola, 1993.

HISTÓRICO das distorções do PCS. FENAE Agora, ano 11, n. 56, p. 18, jun./jul. 2008.

JINKINGS, N. Trabalho e resistência na 'fonte misteriosa': os bancários no mundo da eletrônica e do dinheiro. Campinas, SP: Editora da Unicamp, 2002.

MACHADO, E. G. Campeões, curingas e robôs: os funcionários e a reestruturação no Banco do Brasil. Dissertação de mestrado apresentada ao Programa de PósGraduação em Sociologia da Universidade Federal da Paraíba. João Pessoa, 2002.

MATTOS, E.M. Como a CEF obteve lucro. Gazeta Mercantil. São Paulo, 23 nov. 1994

NEGOCIAÇÃO Coletiva - 2006. Caixa Econômica Federal. Brasília, 2006. Disponível em:

$<$ http://www1.caixa.gov.br/popup/Negociacao/Asp/Duvidas_Frequentes.asp>. Acessado em: jan. 2009.

O MAMUTE está sem fôlego. Exame. São Paulo, p. 42-43, 10 jun. 1992.

OLIVEIRA, R.G. Gerações de trabalhadores no trabalhobancário estatal: uma disputa pela dominação do espaço. ENFOQUES on-line. V.8, n.1 (junho, 2009). Rio de Janeiro: PPGSA, 2009.

PRADO, M. C. R. M. Medidas para sanear a CEF. Gazeta Mercantil. São Paulo, 11 dez. 1992.

REAÇÃO inibida. FENAE Agora. São Paulo, ano 1, n. 1, p. 24, fev. 1998.

SCHMITZ, A.; MAHL, A. A. Reestruturação e automação bancária versus emprego: um balanço ao final dos anos 90. Teor. Evid. Econ. Passo Fundo. v. 8, n. 15, p. 6782, novembro 2000. 
SEGNINI, L. R. P. Reestruturação nos Bancos no Brasil: desemprego, subcontratação e intensificação do trabalho. Educação \& Sociedade, ano XX, no 67, ago. 1999.

SENNETT, R. A corrosão do caráter: as consequências pessoais do trabalho no novo capitalismo. Rio de Janeiro: Record, 2008.

SOARES, G. O prejuízo revelado. Veja. São Paulo, p. 84-85, 2 set. 1992.

SOUSA, V. CEF usa seguradora para ganhar mercado. Folha de São Paulo. São Paulo, 07 set. 1996.

SOUSA, V. Programa da CEF prevê 6.300 demissões. Folha de São Paulo. São Paulo, 26 dez. 1995.

\footnotetext{
${ }^{1}$ Professora da UFGD. E-mail: ramartins@ig.com.br

${ }^{2}$ A conclusão do estágio probatório representava a imediata ascensão em cinco níveis salariais para os escriturários.

${ }^{3}$ A partir de 1993, a empresa não mais promoveu a promoção por mérito (HISTÓRICO..., 2008).

RECEBIDO EM: 10.05.2012

APROVADO EM: 22.06.2012
} 